\title{
A COMPARATIVE STUDY OF CLINICAL EFFECTS OF SPINAL BUPIVACAINE VERSUS SCIATIC-FEMORAL NERVE BLOCK (ANTERIOR APPROACH) IN HIGH RISK GERIATRIC PATIENT FOR LOWER LIMB ORTHOPAEDIC PROCEDURES
}

\author{
Soumi Maiti', Bidyutbikhas Gharami², Dipasri Bhattacharya ${ }^{3}$, Amit Kumar Ray $^{4}$
}

${ }_{1}^{1}$ Senior Resident, Department of Anaesthesiology, R. G. Kar Medical College and Hospital, Kolkata. ${ }^{2}$ Associate Professor, Department of Anaesthesiology, R. G. Kar Medical College and Hospital, Kolkata. ${ }^{3}$ Professor, Department of Anaesthesiology, R. G. Kar Medical College and Hospital, Kolkata. ${ }^{4}$ Assistant Professor, Department of Anaesthesiology, R. G. Kar Medical College and Hospital, Kolkata.

\begin{abstract}
BACKGROUND

Spinal anaesthesia is widely used for lower limb orthopaedic procedure in all age groups. The procedure is safe, but may lead to cardiovascular instability in high risk geriatric patient. Recently, sciatic-femoral nerve block is being used with satisfactory result.

The aim of the study was to compare the onset and duration of sensory and motor blockade, intensity and duration of postoperative analgesia, intraoperative and postoperative haemodynamics in between two groups, one receiving spinal anaesthesia and the other sciatic-femoral block (Anterior approach) in high risk geriatric age group.
\end{abstract}

\section{MATERIALS AND METHODS}

A randomised single-blinded clinical study was done on 60 ASA II and III geriatric patients undergoing lower limb orthopaedic procedure. In Group A ( $\mathrm{n}=30$ ) patients received spinal anaesthesia with $2.5 \mathrm{~mL} 0.5 \%$ hyperbaric bupivacaine and Group B ( $\mathrm{n}=$ 30) patients received sciatic-femoral block (Anterior approach) with $30 \mathrm{~mL}$ and $20 \mathrm{~mL} 0.25 \%$ bupivacaine respectively with nerve locator. Onset and duration of sensory and motor block, duration of analgesia, intensity of analgesia by Visual Analogue Scale (VAS) and haemodynamics (Blood pressure, Heart rate) were recorded. Side effects if any were noted.

\section{RESULT}

Our study revealed later onset of both sensory and motor block, but prolonged duration of analgesia in sciatic-femoral block compared to spinal anaesthesia. The result was statistically significant. Sciatic-femoral nerve block group had stable haemodynamics compared to spinal anaesthesia group $(\mathrm{p}<0.05)$.

\section{CONCLUSION}

To conclude combined sciatic-femoral nerve block (Anterior approach) is a better alternative to spinal anaesthesia in high risk geriatric patients for lower limb orthopaedic procedure.

\section{KEYWORDS}

Spinal Anaesthesia, Sciatic-Femoral Block (Anterior Approach), Lower Limb Orthopaedic Surgery, High Risk Geriatric Patients.

HOW TO CITE THIS ARTICLE: Maiti S, Gharami B, Bhattacharya D, et al. A comparative study of clinical effects of spinal bupivacaine versus sciatic-femoral nerve block (anterior approach) in high risk geriatric patient for lower limb orthopaedic procedures. J. Evolution Med. Dent. Sci. 2017;6(30):2422-2427, DOI: 10.14260/Jemds/2017/523

\section{BACKGROUND}

Administration of anaesthesia in geriatric age group patients is always a challenging task, because they suffer from different co-morbidities like COPD, hypertension, diabetes with decreased pulmonary and cardiac reserve. Most of these patients cannot even tolerate haemodynamic instability during peri-operative periods. ${ }^{1,2}$ Lower limb orthopaedic surgery is associated with significant pain, which results in increase in loss of work and hospital admission.3,4,5 Spinal anaesthesia has been used since many years for lower limb orthopaedic surgery with satisfactory result, but may produce haemodynamic instability in high risk geriatric patients. $6,7,8$

Financial or Other, Competing Interest: None.

Submission 24-02-2017, Peer Review 30-03-2017,

Acceptance 05-04-2017, Published 13-04-2017.

Corresponding Author:

Dr. Soumi Maiti,

\#64, Rajkumar Mukherjee Road,

Alambazar, Baranagar, Kolkata-700035.

E-mail:rgkmch2009@gmail.com

DOI: $10.14260 /$ jemds $/ 2017 / 523$
Recently, sciatic-femoral nerve block (Anterior approach) is also being administered for lower limb orthopaedic surgery. It provides excellent post-operative analgesia with minimal motor block and results in earlier and improved rehabilitation.9,10,11,12 There are various methods to perform this sciatic femoral block. Sciatic block with anterior approach reduces patient discomfort. Positioning of the patients, particularly in this age group with lower limb fracture for sciatic nerve block in posterior approach is very difficult due to pain and/or skeletal traction (Often applied in fracture lower limb).13 For complex knee orthopaedic procedure combined sciatic-femoral nerve block (Anterior approach) is associated with less pain and for outpatient knee surgery it is better than spinal anaesthesia in terms of significantly lower pain score during post-operative periods with early ambulation and faster discharge.14,15,16,17,18,19 Peripheral nerve block becoming increasingly popular ${ }^{20}$ is relatively under-used, because it takes additional time for block performance (Delayed onset time). ${ }^{21}$ So we proposed to conduct the study to compare onset and duration of motor and sensory block, duration and intensity of post-operative analgesia, intraoperative and post-operative haemodynamics, 
dose of phenylephrine required, time of rescue analgesic, side effects, patient's satisfaction score of spinal anaesthesia and sciatic-femoral nerve block (Anterior approach) for lower limb orthopaedic surgery.

\section{MATERIALS AND METHODS}

After approval from the Institutional Ethical Committee and written informed consent from the patients, 60 patients undergoing lower limb orthopaedic procedure were allocated randomly into two groups. The study was single-blinded, randomised clinical trial. Group A $(n=30)$ received spinal anaesthesia and Group B $(\mathrm{n}=30)$ received sciatic-femoral nerve block (Anterior approach). The inclusion criteria were-

- Both sex (Male/Female).

- $\quad$ Age- 65 yrs. -75 yrs.

- $\quad$ Body weight- $40 \mathrm{~kg}-70 \mathrm{~kg}$

- $\quad$ ASA Physical status- II, III

- Patients with controlled co-morbid conditions.

\section{The Exclusion Criteria were-}

- Patient refusal.

- $\quad$ ASA Physical status- I and IV.

- Spinal deformity (If any).

- Contraindication to regional anaesthesia.

- Allergic to local anaesthetic.

- Pre-existing neurological deficit.

- Uncontrolled co-morbid conditions.

- $\quad$ Psychiatric illness.

- $\quad$ BMI > 35, haemoglobin, total count, differential count, erythrocyte sedimentation rate, urea, creatinine, sugar (fasting and post-prandial blood sugar), chest x-ray (PA view), ECG and echocardiography were performed in all the patients in both the groups.

In the operation room the monitors like NIBP, ECG and Pulse oximeter were attached to all patients. All patients received intravenous infusion of Ringer's solution or Ringer's lactate at the rate of $10 \mathrm{~mL} / \mathrm{kg}$ over 20 - 30 minutes before operation. Group A received spinal anaesthesia. Patient was placed in lateral position and the procedure was explained to the patient. After proper antiseptic dressing and draping skin infiltration was done with $1-2 \mathrm{~mL}$ of lignocaine at $\mathrm{L}_{3}-\mathrm{L}_{4}$ vertebral interspace, lumbar puncture was performed through midline approach using 25-gauge Quincke spinal needle. Bupivacaine $0.5 \%$ hyperbaric solution $2.5 \mathrm{~mL}(12.5$ $\mathrm{mg}$ ) was given through spinal needle when free flow of cerebrospinal fluid was evident. After that the syringe with the needle was removed and puncture site was sealed with sterile dressing and sticking plaster. Then the patient was placed in supine position. Blood pressure and heart rate were recorded immediately before and just after the spinal anaesthesia, thereafter 5 minutes interval until the end of the surgery. The upper level of sensory anaesthesia was checked at 2 minutes after the spinal injection by using pinprick sensation and level to reach $\mathrm{T}_{10}$ dermatome was noted. Motor power was assessed by straight leg raising while lying supine and was graded as normal, moderate, impaired and absent and time taken to reach complete paralysis was noted.

In Group B patients received sciatic-femoral nerve block using nerve locator. After explaining the procedure, the patient was placed in supine position with leg extended. Surface marking of inguinal ligament was drawn (A line between anterior superior iliac spine and symphysis pubis). Femoral artery was palpated over inguinal ligament was marked. Needle entry point for femoral nerve block was marked at $1-1.5 \mathrm{~cm}$ lateral and $1-1.5 \mathrm{~cm}$ below to the mid inguinal ligament with a skin marker. Line representing the inguinal ligament was divided into three equal parts. Another line was drawn parallel to the Inguinal ligament from the cephalad aspect of the greater trochanter. A third line (from the intersection of middle and medial third of the $1^{\text {st }}$ line) was drawn perpendicularly to intersect the second line. This intersection point was the point of needle insertion for sciatic nerve block (Anterior approach) and was marked. After proper antiseptic dressing, draping skin infiltration was done at both the point of needle insertion with $2-4 \mathrm{~mL}(1-2 \mathrm{~mL}$ for each) $1 \%$ lignocaine. Positive and negative electrode of the nerve stimulator was attached to the patient and the stimulator needle respectively. Nerve stimulator was set at 0.5 to $1.0 \mathrm{~mA}$. A $50-\mathrm{mm}$ needle was introduced at the abovementioned point for femoral nerve block. A brisk patellar and/or quadriceps twitching with current at $0.5 \mathrm{~mA}$ was achieved. The syringe with $20 \mathrm{~mL} 0.25 \%$ bupivacaine was attached to the needle. After aspiration, the local anaesthetic was injected and cessation of motor twitch was observed. For sciatic nerve block $100 \mathrm{~mm}$ needle was used. Plantar flexion and dorsiflexion was achieved at a current of $0.5 \mathrm{~mA}$ or less. Syringe with $30 \mathrm{~mL} 0.25 \%$ bupivacaine was attached to the needle. Drug was injected with frequent aspiration and the needle was withdrawn. Both the puncture sites were sealed with sterile dressing and sticking plaster. When complete loss of pinprick sensation and inability to elevate the leg was observed, surgery started. Onset and duration time of sensory and motor block were recorded. Intra- and postoperative haemodynamics (Blood pressure and heart rate) were recorded at 5-minutes interval till the end of surgery. Postoperative haemodynamic monitoring was done for 24 hours for every patient. Total duration of analgesia (Onset of analgesia to requirement of rescue analgesic) and intensity of pain in post-operative period were recorded by Visual Analogue Scale (VAS) between $0-10 \mathrm{~cm}(0=$ no pain, $10=$ most severe pain). Any other complications were also looked for. Rescue analgesic was given when VAS score was $\geq 3$ and/or on patient's demand. Study was ended when patient received rescue analgesic.

\section{Sample Size of the Study-}

Sample size $(\mathrm{N})=\frac{(\boldsymbol{Z} \boldsymbol{\alpha}+\boldsymbol{Z} \boldsymbol{\beta})^{2} \mathbf{2} \boldsymbol{s}^{2}}{\boldsymbol{d}^{2}}$

Where $\mathrm{Z} \alpha$ denotes $95 \%$ confident limit 1.65

$\mathrm{Z} \beta$ denotes power of the test, i.e. $90 \%=1.28, \mathrm{~S}=$ mean variance $^{15}$

$\mathrm{d}=$ was the assumed minimum difference to be required for any substantial/clinical/other benefit

$$
\begin{aligned}
\text { Sample size }=(\mathrm{N}) & =\frac{(1.65+1.28)^{2} 2(34)^{2}}{(30)^{2}} \\
& =21.8 \approx 22
\end{aligned}
$$


Twenty-two patients were included in each arm; however, 30 subjects were incorporated in each arm for minimum sample size.

Total patient $=60$.

They were randomly allocated in two groups. Group $(\mathrm{A})=$ spinal anaesthesia $=30$ Group $(B)=$ sciatic-femoral nerve block $=30$.

\section{RESULTS}

Study result showed no statistically significant differences in demographic parameters and duration of operation in between the groups (Table 1). Mean time of onset of sensory block was later in Group - B (Mean 11.40 mins.) than in Group A (Mean 4.67 mins.) and this was statistically significant $(\mathrm{P}<$ 0.005 , Table 2). Mean time of onset of motor block was later in Group B (Mean 16.30) than in Group A and this was statistically significant $(\mathrm{P}<0.005$, Table 2). Mean time of duration of sensory block was greater in Group B (518.07) than in Group A (165.23) and this was statistically significant ( $\mathrm{P}<0.005$, Table 2). Mean time of duration of motor block was greater in Group B (294.97) than in Group A (144.17) and this was also statistically significant $(\mathrm{P}<0.005$, Table 2$)$. Mean duration of analgesia in Group B was more (607.57) than Group A (183.97) and this was statistically significant ( $\mathrm{P}<0.005$, Table 3). Intraoperative haemodynamics study of spinal group of patients showed more mean arterial pressure (Figure 1) using an ANOVA with repeated measures with a Greenhouse-Geisser correction, the mean scores for MAP were statistically significantly different $F=15.297, p=0.000$ and heart rate (Figure 2) variation than sciatic-femoral group of patients and were statistically significant $(\mathrm{p}<0.005)$. VAS score was more in spinal group of patients than sciaticfemoral group and that was statistically significant $(p<0.005$,
$\mathrm{F}=41.756$, Figure 3); $52.6 \%$ of the patients in Group B had no adverse effect in comparison to $47.4 \%$ of the patients in Group A, though this was statistically non-significant on Chi Square Test (p 0.119, Table 4). Questionnaire on consent for the repetition of same anaesthetic procedure if needed, $53.6 \%$ of the patients in Group B gave affirmative answer in comparison to $46.4 \%$ of the patients in Group A and this was statistically significant on Chi Square Test (p 0.038, Table 5). Hypotension (Fall in blood pressure $>20 \%$ of the preoperative value) was observed only in spinal group of patients, so phenylephrine was given only in Group- A patients and this intervention was not done in Group- B patients. For this reason, no statistical analysis was done comparing the dose of phenylephrine required; $40 \%$ of the Group- A patient required phenylephrine.

\begin{tabular}{|c|c|c|c|}
\hline Variable & $\begin{array}{c}\text { Group A } \\
(\mathbf{n = 3 0 )}\end{array}$ & $\begin{array}{c}\text { Group B } \\
(\mathbf{n}=\mathbf{3 0})\end{array}$ & P \\
\hline Age in Yrs. & $68.93(2.840)$ & $69.60(2.896)$ & 0.37 \\
\hline Gender (F/M) & $15 / 15$ & $13 / 17$ & 0.60 \\
\hline Weight in kg & $60.40(4.847)$ & $59.47(4.04)$ & 0.42 \\
\hline Height in cm & $166(10)$ & $169(5)$ & 0.15 \\
\hline $\begin{array}{c}\text { Duration of } \\
\text { Operation } \\
\text { in min }\end{array}$ & $\begin{array}{c}92.50 \\
(32.370)\end{array}$ & $\begin{array}{c}89.67 \\
(25.829)\end{array}$ & 0.709 \\
\hline \multicolumn{3}{|c|}{$\begin{array}{c}\text { Table 1. Demographic variables Qualitative } \\
\text { and Quantitative and Duration of Operation }\end{array}$} \\
\hline
\end{tabular}

Mean and (SD)

\begin{tabular}{|c|c|c|c|c|c|c|c|c|}
\hline & \multirow{2}{*}{ Group } & \multirow{2}{*}{$\mathbf{N}$} & \multirow{2}{*}{ Mean } & \multirow{2}{*}{ Std. Deviation } & \multirow{2}{*}{$\mathbf{t}$} & \multirow{2}{*}{ Sig. (2- Tailed) } & \multicolumn{2}{|c|}{$95 \%$ CI } \\
\hline & & & & & & & Lower & Upper \\
\hline \multirow{2}{*}{$\begin{array}{l}\text { Onset of Sensory } \\
\text { Block (Min) }\end{array}$} & A & 30 & 4.67 & 1.446 & \multirow{2}{*}{-14.191} & \multirow{2}{*}{.000} & \multirow{2}{*}{-7.686} & \multirow{2}{*}{-5.781} \\
\hline & B & 30 & 11.40 & 2.159 & & & & \\
\hline
\end{tabular}

\begin{tabular}{|c|c|c|c|c|c|c|c|c|}
\hline $\begin{array}{c}\text { Onset of Motor } \\
\text { Block (Min) }\end{array}$ & $\mathrm{A}$ & 30 & 6.93 & 1.552 & \multirow{2}{*}{-18.371} & .000 & -10.390 & -8.343 \\
\cline { 2 - 5 }
\end{tabular}

\begin{tabular}{|c|c|c|c|c|c|c|c|c|}
\hline \multirow{2}{*}{$\begin{array}{c}\text { Duration of Sensory } \\
\text { Block (Min) }\end{array}$} & $\mathrm{A}$ & 30 & 165.23 & 8.345 & \multirow{2}{*}{-25.8555} & \multirow{2}{*}{.000} & \multirow{2}{*}{-380.714} & \multirow{2}{*}{-324.953} \\
\hline & $\mathrm{B}$ & 30 & 518.07 & 74.279 & & & & \\
\hline \multirow{2}{*}{$\begin{array}{l}\text { Duration of Motor } \\
\text { Block (Min) }\end{array}$} & $\mathrm{A}$ & 30 & 144.17 & 12.698 & \multirow{2}{*}{-15.007} & \multirow{2}{*}{.000} & \multirow{2}{*}{-171.262} & \multirow{2}{*}{-130.338} \\
\hline & $\mathrm{B}$ & 30 & 294.97 & 53.554 & & & & \\
\hline
\end{tabular}

\begin{tabular}{|c|c|c|c|c|c|c|c|c|}
\hline & \multirow{2}{*}{ Group } & \multirow{2}{*}{$\mathbf{N}$} & \multirow{2}{*}{ Mean } & \multirow{2}{*}{ Std. Deviation } & \multirow{2}{*}{$\mathbf{t}$} & \multirow{2}{*}{$\begin{array}{l}\text { Sig. (2- } \\
\text { Tailed) }\end{array}$} & \multicolumn{2}{|c|}{$95 \%$ CI } \\
\hline & & & & & & & Lower & Upper \\
\hline \multirow{2}{*}{$\begin{array}{c}\text { Duration of } \\
\text { Analgesia (Min) }\end{array}$} & A & 30 & 183.97 & 8.231 & \multirow{2}{*}{-25.835} & \multirow{2}{*}{.000} & \multirow{2}{*}{-457.110} & \multirow{2}{*}{-390.090} \\
\hline & B & 30 & 607.57 & 89.429 & & & & \\
\hline
\end{tabular}




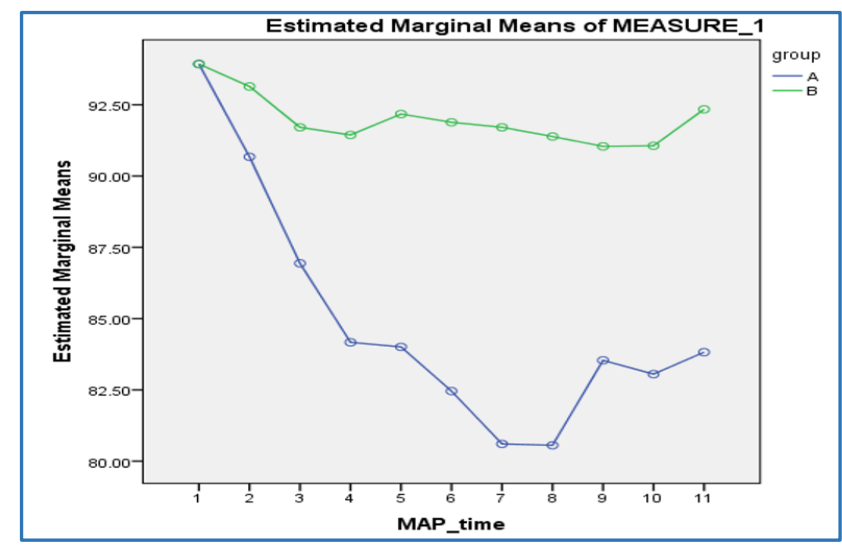

Figure 1. Intraoperative Map

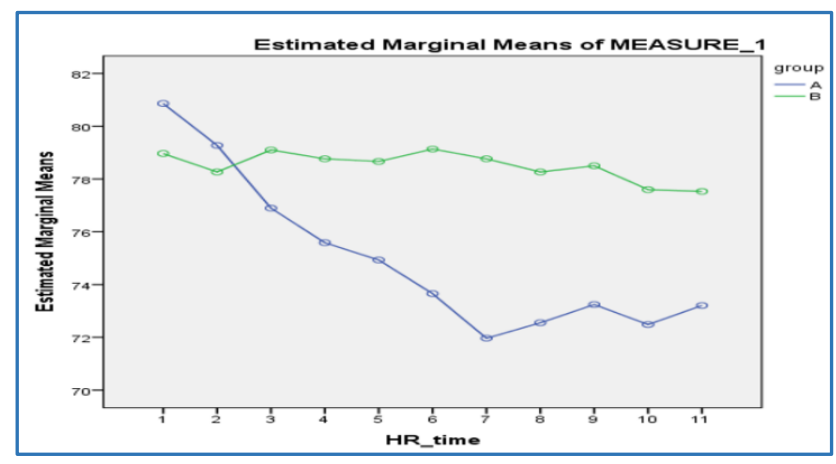

Figure 2. Intraoperative Heart Rate

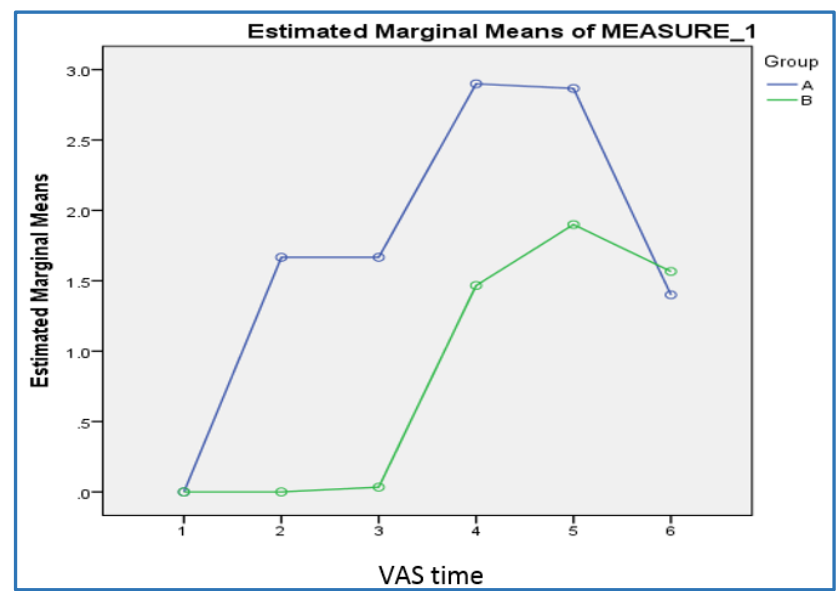

Figure 3. VAS

\begin{tabular}{|c|c|c|c|c|c|}
\hline $\begin{array}{l}\text { Any Adverse } \\
\text { Effect }\end{array}$ & $\begin{array}{c}\text { Group } \\
\text { A }\end{array}$ & $\begin{array}{c}\text { Group } \\
\text { B }\end{array}$ & Total & $\begin{array}{c}\text { Chi } \\
\text { Square }\end{array}$ & $\begin{array}{c}\mathbf{P} \\
\text { value }\end{array}$ \\
\hline N & 27 & 30 & 57 & \multirow{4}{*}{3.158} & \multirow{4}{*}{0.119} \\
\hline No & $47.4 \%$ & $52.6 \%$ & $100.0 \%$ & & \\
\hline \multirow{2}{*}{$\begin{array}{l}\text { Yes (Urinary } \\
\text { Retention) }\end{array}$} & 3 & 0. & 3 & & \\
\hline & $100.0 \%$ & $0.0 \%$ & $100.0 \%$ & & \\
\hline Total & 30 & 30 & 60 & & \\
\hline
\end{tabular}

\begin{tabular}{|c|c|c|c|c|c|}
\hline $\begin{array}{c}\text { Patient } \\
\text { Satisfaction }\end{array}$ & $\begin{array}{c}\text { Group } \\
\text { A }\end{array}$ & $\begin{array}{c}\text { Group } \\
\text { B }\end{array}$ & Total & $\begin{array}{c}\text { Chi } \\
\text { Square }\end{array}$ & $\begin{array}{c}\text { P } \\
\text { value }\end{array}$ \\
\hline \multirow{2}{*}{ No } & 4 & 0 & 4 & & \\
& $100.0 \%$ & $0.0 \%$ & $100 \%$ & \multirow{2}{*}{4.286} & \multirow{2}{*}{0.038} \\
\hline \multirow{2}{*}{ Yes } & 26 & 30 & 56 & & \\
\cline { 2 - 4 } Total & $46.4 \%$ & $53.6 \%$ & $100.0 \%$ & & \\
\hline \multicolumn{7}{|c|}{$\mathbf{3 0}$} & $\mathbf{3 0}$ & $\mathbf{6 0}$ & & \\
\hline \multicolumn{7}{|c|}{ Table 5. Patient Satisfaction } \\
\hline
\end{tabular}

\section{DISCUSSION}

The study result showed onset of sensory and motor blockade was faster in spinal group compared to peripheral nerve block, but duration of both blockade was significantly lower with spinal anaesthesia. ${ }^{6}$ Intraoperative haemodynamic (MAP, HR) instability was less in sciatic femoral blockade with much less VAS scores and better patient satisfaction.

Imbelloni LE, Ganem EM and others compared the unilateral spinal anaesthesia with Sciatic-Femoral block regarding the time required to perform both the blockade, effectivity of the block, haemodynamic effects, adverse reactions and time of discharge in patients with below knee outpatient orthopaedic surgery. Hypotension bradycardia were not observed in any group. 6 The duration of both sensory and motor blockade was less in patients who received spinal block. Patient satisfaction was similar in both groups $(\mathrm{p}=0.23) .{ }^{6}$ In our study, we also observed the mean duration of sensory and motor blockades was significantly less with spinal anaesthesia compared to combined sciatic femoral nerve block $(\mathrm{p}<0.0005)$.

Spasiano A, Flore I and others compared spinal anaesthesia and sciatic-femoral block for arthroscopic knee surgery. Patients who received spinal block showed decreased heart rate $(\mathrm{p}<0.05)$. Patients' satisfaction scale was similar in both the groups. ${ }^{6}$ Peripheral nerve block was associated with haemodynamic stability, 7 earlier urine output and faster discharge. ${ }^{7}$ In our study, we also found decreased heart rates in spinal anaesthesia group and this was statistically significant $(\mathrm{p}<0.005)$.

Fanelli G, Aldegheri G and others (1998) studied the cardiovascular effects of unilateral spinal and combined sciatic-femoral block. Patients in Nerve Block (NB) group did not show any haemodynamic changes, but patients in neuraxial group showed significant decrease of mean arterial blood pressure. So, peripheral nerve block affects cardiovascular system lesser than spinal block.7,8 In our study, we also observed more decrease in mean arterial pressure in spinal group compared to sciatic-femoral group.

Casati A, Cappelleri G and others (2000) - carried out a prospective, randomised study comparing the spinal and sciatic-femoral block in outpatient knee surgery. Onset of motor and sensory blockade were also faster in spinal group compared to peripheral nerve block group $(p=0.0002)$. First time of urine output was longer in the patients who received spinal block than the patients receiving peripheral nerve block $6,7,16(p<0.0005$ and $p=0.002)$. Peripheral nerve block provided better postoperative analgesia.16,21 In our study we found mean duration of analgesia in sciatic femoral group was more than spinal $(\mathrm{p}<0.005)$.

Cappelleri G, Casati A and others (2000) compared the time required to achieve sensory block, discharge, cardiovascular parameters between unilateral spinal and sciatic femoral block, both provided adequate anaesthesia and similar discharge criteria.22,23,24,25 The result is similar to our study result. Sansone and others in their study showed $82 \%$ patients undergoing ACL reconstruction getting sciatic femoral block bypassed post-anaesthetic care unit.26,27 It supports the results of our study.

Montes FR, Zarate E and others compared low-dose spinal anaesthesia with combined sciatic-femoral block. Patients in both groups had same pain score in recovery room, but after discharge patients who received sciatic-femoral block had 
low pain score $(10 \pm 24 \mathrm{~mm})$ than with the patients receiving spinal block $(50 \pm 35, p=0.002)$. Patients who received sciatic-femoral block required less analgesic during first 6 hours of postoperative period than the patients receiving spinal block. ${ }^{23,25}$ In our study, the mean VAS score was lower in sciatic-femoral group ( $\mathrm{P}<0.005)$.

Jansen TK and others compared femoral nerve block with combined sciatic-femoral nerve block in patients undergoing anterior cruciate ligament repair regarding pain score, analgesic requirement and patients' satisfaction. Patients receiving sciatic-femoral block required less analgesic than the patients who received femoral block alone. Postoperative analgesia, patients' satisfaction both were better in the patients receiving combined sciatic-femoral block than the patients with femoral block alone. ${ }^{28}$ In our study, similar results were obtained.

Casati A, Grispignic C and others compared sciatic femoral block with both unilateral and bilateral spinal anaesthesia. There was significantly lower number of cases of sciatic femoral block who had postoperative urinary retention. Prolonged analgesia was observed in all these cases. ${ }^{29}$ Our study also proved less adverse effect and longer postoperative analgesia in sciatic femoral group $(\mathrm{p}<0.005)$.

There are various approaches to perform sciatic-femoral block. Posterior, lateral and anterior approach. Both posterior and lateral approach needs movement of the patient, change of posture while performing the block. Elderly people may feel extreme discomfort and pain during change of posture. So we preferred to block sciatic nerve through anterior approach with practically minimal movement of the patient.

A case report was done by Maitra G, Kunar P and others (2007) regarding the patient with restrictive cardiomyopathy who received sciatic-femoral block for arthroscopy. It was observed that combined sciatic-femoral block was safe as there was no haemodynamic instability and it also provided excellent postoperative analgesia. ${ }^{30,31,32}$ Our study also proved better intraoperative and postoperative haemodynamics in sciatic femoral group and this was statistically significant $(\mathrm{p}<0.005)$.

Baddoo HK reported a case where sciatic-femoral block was performed on the patient for below knee amputation. It was observed that peripheral nerve block can be used effectively for lower limb amputation without haemodynamic instability. 33 Our study revealed all lower limb procedures are better tolerated in sciatic femoral group (Anterior approach).

Vidyathri and others conducted a retrospective cohort study in level 2 trauma care centre regarding feasibility, indications, complications of sciatic-femoral block for all orthopaedic surgeries below and around the knee, especially in a compromised setup. Preoperatively, they assessed the time of onset of the block, failure rate, adequacy of the block. Preoperatively, they assessed duration and quality of the block and postoperative parameters were duration of postoperative analgesia, requirement of analgesic and complications. Their study showed that $80 \%$ to $90 \%$ patients developed adequate analgesia. Sciatic femoral block provided cardiovascular stability, good postoperative analgesia with no complication. ${ }^{34}$

\section{CONCLUSION}

From this study, we observed that duration of sensory block, motor block and post-operative analgesia were more prolonged in case of sciatic-femoral nerve block than spinal anaesthesia. Sciatic-femoral block (Anterior approach) was associated with stable haemodynamic, lesser complications and is better tolerated by patient with good satisfaction scale compared to spinal anaesthesia. So, we can conclude that sciatic-femoral nerve block (Anterior approach) is a better alternative than spinal anaesthesia in case of high risk geriatric patients undergoing lower limb orthopaedic procedure.

\section{REFERENCES}

[1] Bergmann I, Heetfeld M, Crozier TA, et al. Peripheral nerve block give greater hemodynamic stability than general anaesthesia for ASA III patients undergoing outpatient knee arthroscopy. Central European Journal of Medicine 2013;8(4):436-42.

[2] Hemmingsen C, Følsgaard SL, Frey-Larsen S, et al. Risk and haemodynamic instability in spinal anaesthesia. Ugeskr Laeger 1991;153(15):1052-5.

[3] Wang H, Boctor B, Verner J. The effect of single injection femoral nerve block on rehabilitation and length of hospital stay after total knee replacement. Reg Anesth Pain Med 2002;27(2):139-44.

[4] Spasiano A, Flore I, Pesamosca A, et al. Comparison between spinal anaesthesia and sciatic-femoral block for arthroscopic knee surgery. Minerva Anestesiol 2007;73(1-2):13-21.

[5] Williams BA, Kentor ML, Vogt MT, et al. Femoralsciatic nerve blocks for complex outpatient knee surgery are associated with less postoperative pain before same-day discharge: a review of 1,200 consecutive cases from the period 1996-1999. Anaesthesiology 2003;98(5):1206-13.

[6] Imbelloni LE, de Rezende GV, Ganem EM, et al. Comparative study between combined sciatic-femoral nerve block, via a single skin injection, and spinal block anaesthesia for unilateral surgery of the lower limb. Rev Bras Anestesial 2010;60(6):584-92, 324-8.

[7] Casati A, Cappelleri G, Aldegheri G, et al. Total intravenous anaesthesia, spinal anaesthesia or combined sciatic-femoral nerve block for outpatient knee arthroscopy. Minerva Anestesiol 2004;70(6):493-502.

[8] Fanelli G, Casati A, Aldegheri G, et al. Cardiovascular effects of two different regional anaesthetic techniques for unilateral leg surgery. Acta Anaesthesial Scand 1998;42(1):80-4.

[9] Grant CRK, Checketts MR. Analgesia for primary hip and knee arthroscopy: the role of regional anaesthesia. Continuing Education in Anaesthesia, Critical Care and Pain 2008;8(2):56-61.

[10] Capdevila X, Barthelet Y, Biboutlet P, et al. Effects of perioperative analgesic technique on the surgical outcome and duration of rehabilitation after major knee surgery. Anaesthesiology 1999;91(1):8-15. 
[11] Singelyn FJ, Deyaert M, Joris D, et al. Effects of intravenous patient-controlled analgesia with morphine, continuous epidural analgesia, and continuous three-in-on block on postoperative pain and knee rehabilitation after unilateral total knee arthroplasty. Anesth Analg 1998;87(1):88-92.

[12] Ilfeld BM, Geaven PF, Enneking FK, et al. Total knee arthroplasty as an overnight stay procedure using continuous femoral nerve block at home: a prospective feasibility study. Anesth Analg 2006;102(1):87-90.

[13] Pandin P, Vancutsem N, Salengros JC, et al. The anterior combined approach via a single skin injection site allows lower limb anesthesia in supine patients. Can J Anaesth 2003;50(8):801-4.

[14] Williams BA, Kentor ML, Williams JP, et al. Process analysis in outpatient knee surgery: effects of regional and general anesthesia on anesthesia-controlled time. Anaesthesiology 2000;93(2):529-38.

[15] Montes R, Zarate E, Grueso R, et al. Comparison of spinal anesthesia with combined sciatic-femoral nerve block for outpatient knee arthroscopy. Journal of Clinical Anesthesia 2008;20(6):415-20.

[16] Casati A, Cappelleri G, Fanelli G, et al. Regional anaesthesia for outpatient knee arthroscopy: a randomized clinical comparison of two different anaesthetic techniques. Acta Anaesthesiol Scand 2000;44(5):543-7.

[17] Casati A, Cappelleri G, Berti M, et al. Randomized comparison of remifentanil-propofol with a sciaticfemoral nerve block for out-patient knee arthroscopy. Eur J Anaesthesiol 2002;19(2):109-14.

[18] Cappelleri G, Casati A, Fanelli G, et al. Unilateral spinal anesthesia or combined sciatic-femoral nerve block for day-care knee arthroscopy. A prospective randomized comparison. Minerva Anestesiol 2000;66(3):131-6.

[19] Nakamura SJ, Conte- Hernandez A, Galloway MT. The efficacy of regional anesthesia for outpatient anterior cruciate ligament reconstruction. Arthoscopy 1997;13(6):699-703.

[20] Auroy Y, Benhamou D, Bargues L, et al. Major complications of regional anaesthesia in France: the SOS regional anesthesia hotline service. Anaesthesiology 2002;97(5):1274-80.

[21] Klein SM, Evans H, Nielsen KC, et al. Peripheral nerve block techniques for ambulatory surgery. Anesth Analg 2005;101(6):1663-76.

[22] Rizzo D, Giustiniano E, Pellicori D, et al. Sciatic, femoral and cutaneous nerve block for arthroscopic meniscectomy in a patient with eisenmenjer's syndrome. Case report. Minerva Anestesiol 1999;65(10):733-6.
[23] Chia N, Low TC, Poon KH. Peripheral nerve blocks for lower limb surgery-a choice anaesthetic technique for patients with a recent myocardial infraction? Singapore Med J 2002;43(11):583-6.

[24] Jankowski CJ, Hebl JR, Stuart MJ, et al. A comparison of psoas compartment block and spinal and general anesthesia for outpatient knee arthroscopy. Anesth Analg 2003;97(4):1003-9.

[25] Korhonen AM, Vulanne JV, Jokela RM, et al. A comparison of selective spinal anesthesia with hyperbaric bupivacaine and general anesthesia with desflurane for outpatient knee arthroscopy. Anesth Analg 2004;99(6):1668-73.

[26] Williams BA, Kentor ML, Vogt MT, et al. Economics of nerve block pain management after anterior cruciate ligament reconstruction: potential hospital cost savings via associated postanesthesia care unit bypass and same-day discharge. Anaesthesiology 2004;100(3):697-706.

[27] Sansone V, Deponti A, Fanelli G, et al. Combined sciatic and femoral nerve block for knee arthroscopy: 4 years' experience. Arch Orthop Trauma Surg 1999;119(34):163-7.

[28] Jansen TK, Miller BE, Arretche N, et al. Well the addition of a sciatic nerve block to a femoral nerve block provide better pain control following anterior cruciate ligament repair surgery? AANA Journal 2009;77(3):213-18.

[29] Casati A, Grispignic C, Aldegheri G, et al. Peripheral or central nerve blocks for foot surgery: a prospective randomized clinical comparison. Foot and ankle surgery 2002;8(2):95-100.

[30] Maitra G, Kumar P, Sengupta S, et al. Combined sciatic femoral block in a case of restrictive cardiomyopathy for arthroscopy and anterior cruciate ligament (ACL) reconstruction. Indian J Anaesth 2007;51(3):234-6.

[31] Baddoo HK. A preliminary report on the use of peripheral nerve blocks for lower limb amputation. Ghana Med J 2009;43(1):24-8.

[32] Kocum A, Turkoz A, Bozdogan N, et al. Femoral and sciatic nerve block with $0.25 \%$ bupivacaine for surgical management of diabetic foot syndrome: an anesthetic technique for high risk patients with diabetic nephropathy. J Clin Anes 2010;22(5):363-6.

[33] Weihrauch J0, Jehmlich M, Leischik M, et al. Are peripheral nerve blocks of the leg (femoralis in combination with anterior sciatic blockade) as sole anaesthetic technique an alternative to epidural anaesthesia. Anasthesiol Intensivmed Notfallmed Schmerzther 2005;40(1):18-24.

[34] Vidyarthi K, Sharma S, Kakran R, et al. Sciatic-femoral block for all surgeries below and around kneeramification for orthopaedic surgeon in a compromised set up. $\mathrm{Pb}$ Journal of Orthopadics 2011;12(1):61-3. 